\title{
Measuring Selection Diversity of Emergency Medical Service for Metro Stations: A Case Study in Beijing
}

\author{
Zhe Zhang ${ }^{1,2,+}$, Limin Jia ${ }^{1,2, *}$ and Yong Qin ${ }^{1,2}$ \\ 1 State Key Lab of Rail Traffic Control and Safety, Beijing Jiaotong University, Beijing 100044, China; \\ zhangzhe@bjtu.edu.cn (Z.Z.); yqin@bjtu.edu.cn (Y.Q.) \\ 2 Beijing Research Center of Urban Trafc Information Sensing and Service Technologies, \\ Beijing Jiaotong University, Beijing 100044, China \\ * Correspondence: lmjia@bjtu.edu.cn; Tel.: +86-010-5168-3824 \\ + Current address: State Key Lab of Rail Traffic Control and Safety, Beijing Jiaotong University, \\ No. 3 Shangyuancun Haidian District, Beijing 100044, China.
}

Received: 21 May 2018; Accepted: 26 June 2018; Published: 02 July 2018

\begin{abstract}
It is important for station managers and emergency medical service (EMS) managers to understand the available ambulance stations for each metro station. EMS managers can make use of this information to reallocate EMS resources to improve the performance of EMS system. Station managers can pay attention to the safety management of metro stations with fewer medical rescue support. This paper aims to develop a selection diversity index to address two questions: "How many available ambulance stations are available or can serve the rescue of metro stations in emergency?" and "Which ambulance stations are most vulnerable?". To implement this measure in practice, definition of available ambulance stations for rescue of metro stations is described based on the response time threshold. The selection diversity is proposed to measure the preparability of medical rescue service for metro stations. To show proof of concept, a real-world case is presented to demonstrate the feasibility of the selection diversity index.
\end{abstract}

Keywords: emergency medical service; metro station; selection diversity; vulnerability

\section{Introduction}

Metro stations are the important nodes of metro network; incidents in metro stations could result in not only local loss of transportation capacity but also network-wide confusion [1]. Further, metro stations have been suffering from high crowd density for a long time, and the crowding reduces the comfort level and increases the potential of risk [2]. Therefore, when accidents including explosion [3], fire [4] happen in a metro station, passengers will face serious life-threatening situations and should be rescued immediately.

Emergency medical service (EMS) can provide immediate medical service when accidents occur. A well-designed EMS system is crucial for metro emergency rescue when a metro station is being shut down. However, the EMS in a city is designed for rescue of all citizens, not just those using the metro system [5]. Emergency medical rescue centers (ambulance stations) may be busy and their rescue services are not always available [6]. Therefore, it is important to know how many ambulance stations can provide immediate medical service for metro stations when the rescue service of ambulance stations is available or unavailable. In addition, government or EMS managers should know which ambulance stations are vulnerable (i.e., have the largest impact to the overall performance of EMS for metro stations when they are unavailable) in order to make use of the limited workers, ambulances, and financial resources to equip these ambulance stations [7,8]. The main contribution of this paper is to develop a selection diversity index to tackle two critical questions: 
- How many ambulance stations are available or can serve the rescue of metro stations in emergency?

- Which ambulance stations are most vulnerable?

The available ambulance stations concept adopted in this paper refers to the definition in reference [9], which is "a single list associated with each customer (emergency demand point) that ranks the available servers (ambulance stations)' order of dispatch preference". In other words, available ambulance stations are a set of stations that can rescue life of people in emergency efficiently or within a pre-defined time framework. In the set, the ambulance stations are ranked according to the length of response time. Therefore, the available station set is comprised of different ambulance stations and may be ranked variously for different metro stations.

The remainder of this paper is organized as follows: In Section 2, the location study of EMS units and the performance evaluation method of EMS are reviewed. In Section 3, we describe the problem and make some assumptions, and then we present the formula for calculating the number of available ambulance stations, the selection diversity index and the vulnerability. In Section 4, we present one numerical example to demonstrate the feasibility of the measurement and its application on the real-world metro and EMS. Conclusion is given in Section 5.

\section{Literature Review}

Because of the randomness of accident occurrence, an emergency response plan is required. According to the emergency response plan proposed by $[10,11]$, the emergency response of metro stations includes: finding and reporting the emergency situation; ordering the relevant departments to adjust the operation scheme, accident removal and rescue; and resuming the operation of metro stations. Usually, the core part of emergency response is the accident removal and rescue. In the process of accident removal and rescue, emergency service units such as polices, fire stations and emergency medical services are needed. The station staff should help to evacuate the passengers before the emergency service units arrive. Therefore, more and more attention are paid to the location optimization method of emergency service units to improve the performance of EMS.

The location study of emergency service units focuses where to locate emergency service stations in cities. A good location plan should reduce the response time and cover much more emergency demand [12]. The reviews on the location of emergency service facilities can be found in $[13,14]$. However, the objective of location of emergency service units including ambulance stations in the previous study is to cover the emergency demand in a city or area, and the emergency medical service system is not specifically designed for metro or railway accident rescue. Therefore, a strategic planning model has been proposed to solve the railway system accident rescue problem [15].

Although such approaches are very useful in helping to decide the location of ambulance stations, the urban environment is constantly changing. To remain safe, there is a need to monitor and assess the performance of EMS continually [16]. The performance indicators include time/distance indexes such as expected coverage level [17], response time [18], round trip time [19], service time [20] and dispatching time [21], ratio indexes such as loss ratio [22], survival rate [23], and financial index such as capital and operating cost [24]. Many of these indicators reflect the intention of emergency demand or the interest of EMS management [25].

Response time is the most important indicator because reducing the response time is to lessen the impacts and minimize the life and property loss [26,27]. Among the proposed indicators, 3 indicators including the expected coverage, round trip time and survival rate are inferred from the response time. However, there is no agreement on the value of response time threshold. For example the standard specified in the American EMS Act of 1973 required that in urban areas $95 \%$ of requests should be reached within $10 \mathrm{~min}$ and in rural areas, calls should be reached within $30 \mathrm{~min}$ [13]. In reference [15], the required response time threshold is $12 \mathrm{~min}$; In urban areas, the most widely used ambulance response time standard is to respond to $90 \%$ of calls within $8 \mathrm{~min}$ and $59 \mathrm{~s}$ as compared to responding to $90 \%$ of calls within $14 \mathrm{~min}$ and $59 \mathrm{~s}$ in rural areas [28]. 
Robustness refers to the ability of tolerating perturbations that might affect the system's functional body $[29,30]$. For EMS, it reflects the ability to provide medical rescue service when uncertainties occur. In EMS study, a stochastic programming approach has been proposed to design a robust EMS, which is to achieve a reliable level of service and minimize the operation cost [31]. A bi-objective model was developed to design a cost-responsiveness efficient emergency medical services (EMS) system under uncertainty [32], the approach determines the location of EMS stations, the assignment of demand areas to EMS stations, and the number of EMS vehicles at each station to balance cost and responsiveness by using a robust counterpart approach to deal with uncertain demand.

To sum up, many researchers focus on the location study of EMS in static or steady environment except for [33]. However, the traffic status in a city changes with time [34,35]. As a result, the response time which is composed of travel time mostly [15] is different during different periods. The method presented in this paper is to discuss the performance of EMS under the dynamic traffic status. We propose the selection diversity to assess the choice of ambulance stations. Different from the study on vehicle routing which is to reduce the exposure or rescue peoples after the accidents [36], we want to help emergency managers improve the performance of EMS system in the preparedness process of emergency management activities [37]. The selection diversity reflects the robustness of getting EMS for metro stations in emergency when some ambulance stations are busy, supports the evaluation of vulnerability of EMS which is one of three main components of risk management (occurrence, vulnerability and exposure) [38].

\section{Methodology}

In this section, the method framework is proposed firstly and then we describe the definition of available ambulance stations based on the response time analysis, derive the calculation method of selection diversity. Finally, the derivation process of vulnerability of EMS is given.

\subsection{Framework of Method}

The framework of method consists of the two main aspects (Figure 1):

- Data preparation: Because the number of origin-destinations is vary large due to the large number of ambulance stations and metro stations, the common survey method cannot be used to the obtain the travel time data between any ambulance station and metro stations because of the financial and staff cost. Therefore, the crawler method [39] is used to obtain the travel time data from the electronic map.

- Selection diversity analysis: First the definition of available ambulance station is given and the proposed selection diversity is formulated. The selection diversity is analyzed from three aspects: distribution of number of available ambulance stations, spatial distribution of metro stations without EMS support and the most vulnerable ambulance stations. Finally, the discussion and suggestions are given based on the analysis results.

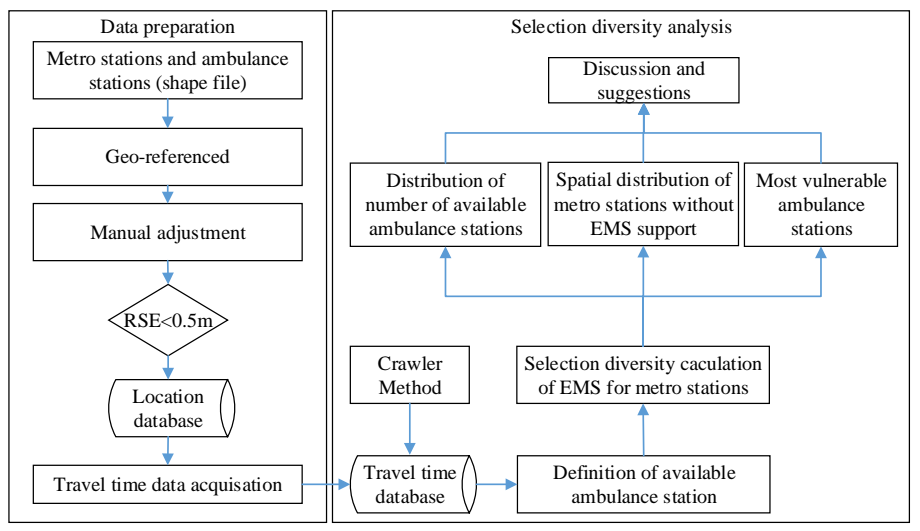

Figure 1. Framework of method. 


\subsection{Available Ambulance Station}

We define that $N$ denotes the numbers of metro stations and $E$ denotes the number of ambulance stations. The metro stations can obtain the emergency medical service in emergency situation if the ambulance stations can serve the rescue of metro stations within a specified response time threshold. The response time can be defined as the time interval between call receipt and arrival on scene and has been used as performance indicators of EMS. Let $t^{r}$ denote the response time, we can get $t^{r}=t^{c}+t^{d}$, in which $t^{c}$ and $t^{d}$ denote the dispatching time and the travel time. Dispatching time is the interval between the receipt of the request and the assignment of an ambulance; the travel time is defined as the driving time from the ambulance stations to the metro stations in emergency situation.

The current dispatch system has realized the importance of a quick response to emergency scenes and thus reduce the dispatching time to a low level (about $30 \mathrm{~s}$ ) [40]. The travel time $t^{d}$ comprise the greatest fraction of response time $t^{r}$ during normal operating period $[18,41,42]$. Therefore, the dispatching time has little effect on the performance of EMS and can be neglected, that is $t^{r} \approx t^{d}$. The same viewpoint is also shared by the reference [15]. We can represent the response time threshold, $t^{m}$, as follows:

$$
t_{i, j}^{d} \leq t^{m}
$$

where $t_{i, j}^{d}$ is the travel time from the ambulance station $j$ to the metro station $i$.

The travel time of ambulance depends on the amount of traffic on the roads between the ambulance station and the metro station. It has been proved that the congestion regime will increase the travel time of ambulances even though ambulances are allowed to make use of their acoustic and/or light signals [43]. The state-dependent travel time can help us design a better EMS system than the deterministic travel time [44]. Therefore, the state-dependent travel time concept is adopted in this paper to evaluate the performance of EMS. The travel time between ambulance stations and metro stations is obtained using the the Gaode map API (Application Programming Interface) because the API provides the interface from which we can visit the online map quickly.

\subsection{Selection Diversity of EMS for Metro Stations}

Let $\sigma_{i, j}$ denotes whether the metro station $i(i=1, \ldots|N|)$ can obtain the EMS from the ambulance station $j,(j=1, \ldots|E|)$ within the response time threshold $t_{m}$. We define that a metro station $i \in N$ is covered by ambulance station $j \in E$ if and only if $t_{i, j}^{d} \leq t_{m}$, that is:

$$
\sigma_{i, j}= \begin{cases}1 & \text { if } t_{i, j}^{d} \leq t^{m} \\ 0 & \text { otherwise }\end{cases}
$$

The number of available ambulance stations for metro station $i$ in emergency $N_{i}$ can be defined as:

$$
N_{i}=\sum_{j=1}^{E} \sigma_{i, j}
$$

The selection diversity of the metro stations in emergency can be defined as the average number of available ambulance stations for each metro station. Mathematically, a selection diversity index $S\left(t_{m}\right)$ can be expressed as:

$$
S\left(t_{m}\right)=\frac{\sum_{i=1}^{N} \sum_{j=1}^{E} \sigma_{i, j}}{|N|}
$$

The ambulance stations may be busy and cannot provide the EMS for the metro stations in emergency and these ambulance stations are defined as unavailable ambulance stations. The unavailable ambulance stations can affect the selection diversity more or less. To measure the 
impact of unavailable ambulance stations, we define the vulnerability of one specific ambulance station $\rho_{k}\left(t_{m}\right)$ as the reduced percentage of selection diversity when the rescue service of ambulance station $k$ is unavailable, that is:

$$
\rho_{k}\left(t_{m}\right)=1-\frac{S_{k}\left(t_{m}\right)}{S\left(t_{m}\right)}
$$

where $S_{k}\left(t_{m}\right)$ is the selection diversity when the rescue service of ambulance station $k$ is unavailable. The $S_{k}\left(t_{m}\right)$ can be formulated as:

$$
S_{k}\left(t_{m}\right)=\frac{\sum_{i=1}^{N}\left(\sum_{j=1}^{k-1} \sigma_{i, j}+\sum_{j=k+1}^{E} \sigma_{i, j}\right)}{N}
$$

Substituting Equations (6) and (4) in Equation (5), we get the following equation to calculate vulnerability.

$$
\rho_{k}\left(t_{m}\right)=\frac{\sum_{i=1}^{N} \sigma_{i, k}}{\sum_{i=1}^{N} \sum_{j=1}^{E} \sigma_{i, j}}
$$

in which the numerator part represents the number of metro stations served by the ambulance station $k$. Equation (7) implies that the ambulance stations which serve more metro stations are more vulnerable when selection diversity is constant. However, the selection diversity depends on the state-dependent travel time according to Equations (3) and (4). Therefore, it is worth identifying the most vulnerable ambulance stations from all stations during different periods.

\section{Numerical Example}

This section presents one numerical example, Beijing metro and EMS, to demonstrate the feasibility of the selection diversity index.

\subsection{Metro Stations and EMS in Beijing}

In this example, the selection diversity index is applied to studying the interaction between the metro stations and EMS.

\section{(1) Location data}

The Beijing Metro network consists of 288 metro stations (sum of stations in operation and under construction), the location data of these metro stations is collected from the official website of the Beijing Mass Transit Railway Operation Corporation. The EMS in Beijing can be divided into two systems, one is Beijing emergency medical service system (120 EMS) which is supported by the government and the other is Red Cross emergency medical service system which supported by a Public welfare organization-Beijing Red Cross (999 EMS). The data about EMS comes from the the official website of two EMS systems http:/ / www.beijing999.com.cn/infoshow.aspx?id=426 and http://www.beijing120.com/channel/184. We collected 121 ambulance stations, among which 86 ambulance stations belong to 120 EMS and 35 ambulance stations belong to 999 EMS. All ambulance stations and metro stations are shown in Figure 2. Figure 2a depicts the locations of metro stations, Figure $2 b$ depicts the locations of ambulance stations and Figure $2 c$ is the overview of ambulance stations and metro stations in Beijing.

(2) Travel time data

According to the location of metro stations and ambulance stations, the number of OD (origin-destination) pairs is 31,848 . It is difficult to get the travel time data by field survey but 
the online map can provide much information about the route planning, navigation and coordinate setting. The online Maps can introduce an innovative approach that maintains a constant connection between service provider and client, and it has been used to plan emergency routes [45], develop applications and create new customized service [46]. Therefore, we use the online map API to obtain the travel time data automatically.

The online map used in this paper is Gaode online map which is used widely in China [47]. We used the software Matlab to establish the link between our computers and the route-plan API of Gaode map, and then obtained the data in xml file format. The xml data involves not only the travel time information but also the text about route navigation. Therefore, we have to develop a parsing algorithm to extract the travel time from the text information. We collect travel time data during morning peak hours (7:00-9:00), evening peak hours (17:00-19:00) and off-peak hours (10:00-16:00) [48] on 28 April, 8 May, and 10 May 2017. The mean value of travel time is used in the following analysis.

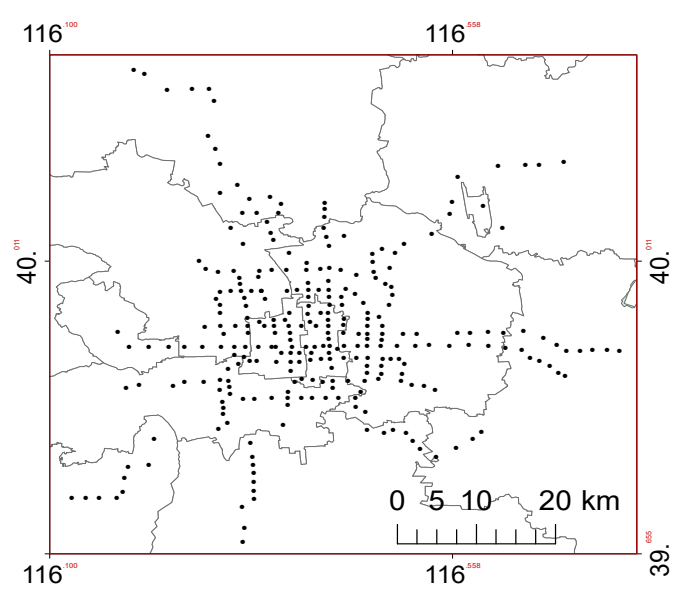

(a) Locations of metro stations in Beijing

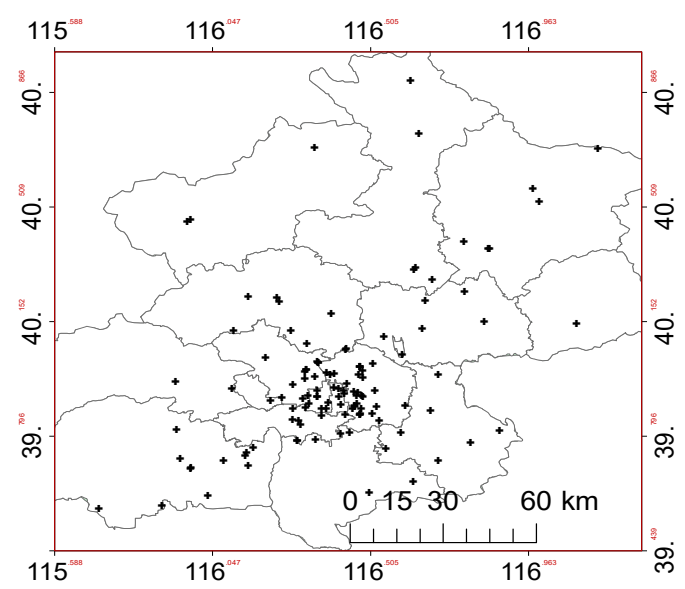

(b) Locations of ambulance stations in Beijing

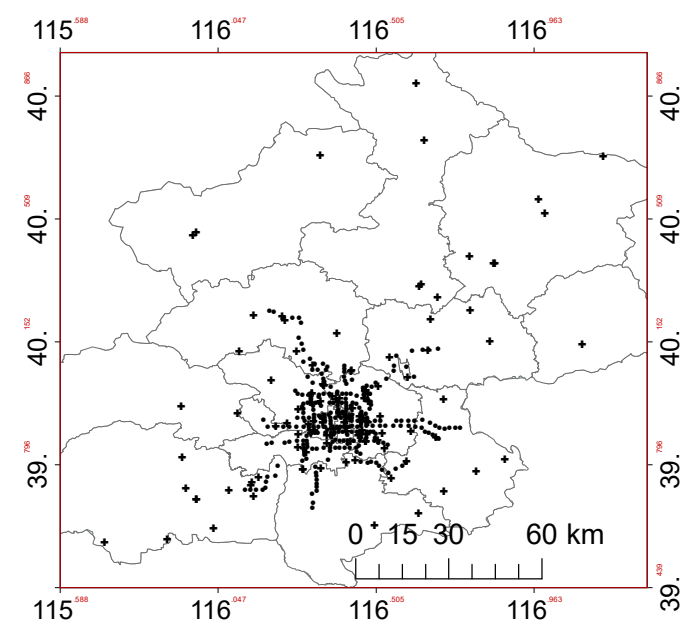

(c) Overview of ambulance stations and metro stations in Beijing

Figure 2. Location data.

In what follows, we use the selection diversity index to address the two questions stated in the abstract: (1) "How many available ambulance stations are available or can be used for the rescue of metro stations in emergency?" and (2) "Which ambulance stations are most vulnerable?". This can be achieved by analyzing 
the distribution of number of available ambulance stations, spatial distribution of metro stations without EMS support and the reduction of selection diversity based on the data and proposed method.

\subsection{Model Results and Discussion}

(1) Distribution of number of available ambulance stations

In this paper, we adopt the value of response time threshold proposed by the reference [15], that is $t_{m}=720 \mathrm{~s}$. The distribution of number of available ambulance stations is depicted in Figure 3 . According to Equation (4) and the data, the selection diversity of EMS $S\left(t_{m}\right)=1.3160$ during morning peak hours, $S\left(t_{m}\right)=1.7778$ during off-peak hours and $S\left(t_{m}\right)=1.2153$ during evening peak hours. The fact means that the average number of ambulance stations that can serve each metro station is 1.3160, 1.7778 and 1.2153 during morning peak hours, off-peak hours and evening peak hours, respectively. The percent of metro stations without EMS support during morning peak hours, off-peak hours and evening peak hours is $0.3264,0.2153$ and 0.3715 , respectively. The fact shows that the congested traffic regime reduces the selection diversity by $26 \%$ and $32 \%$, and increases the number of metro stations without EMS support by $51.6 \%$ and $72.5 \%$ during peak hours. It can be concluded that the more congested the traffic network is, the lower the selection diversity is.

As can be seen from Figure 3, stations 213 and 214 have the greatest number of available ambulance stations (8) during morning peak hours. The node 213 and 214 denote the NanBaLiZhuang Station and BeiGongDaXiMen Station, respectively. The above two stations belong to the Line 14. During off-peak hours, except for node 213, 214, the station 127 and 215 have the maximum number of available ambulance stations. The node 127 and 215 denote the DaJiaoTing Station (Line 7) and the PingLeYuan Station (Line 14). During evening peak hours, except for node 213, 214, 215, the GuangQuMenWai Station has the maximum number of available ambulance stations.

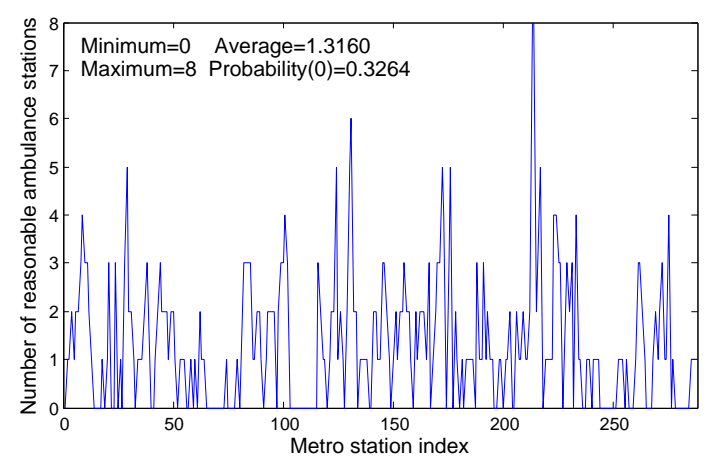

(a) Morning peak hours

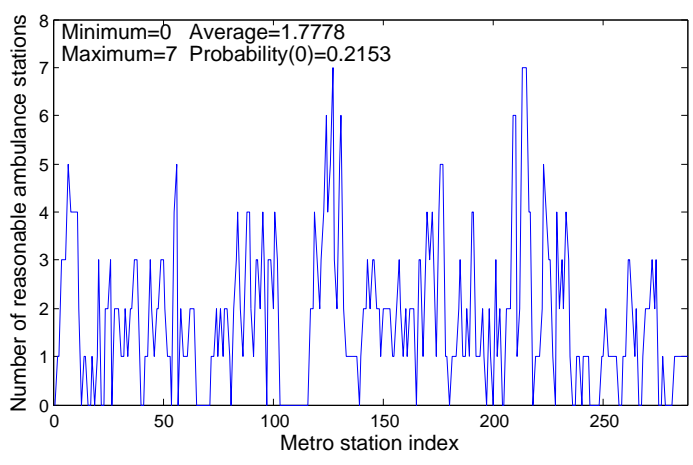

(b) Off-peak hours

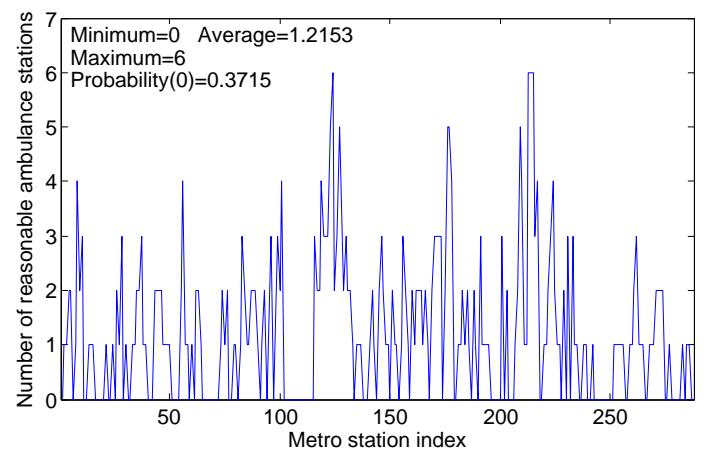

(c) Evening peak hours

Figure 3. Distribution of number of available ambulance stations. 
(2) Spatial distribution of metro stations without EMS support

The metro managers should focus on the safety management of the metro stations without EMS support. so the number and the spatial distribution of metro stations without EMS support was analyzed in this section. The number of metro stations without EMS support is 94,62 and 107 during morning peak, off peak and evening peak hours, respectively, as shown in Figure 4 . The fact shows that EMS supports for metro stations can benefits from the reduction of traffic congestion.

\section{Number of Metro Stations without EMS Support}

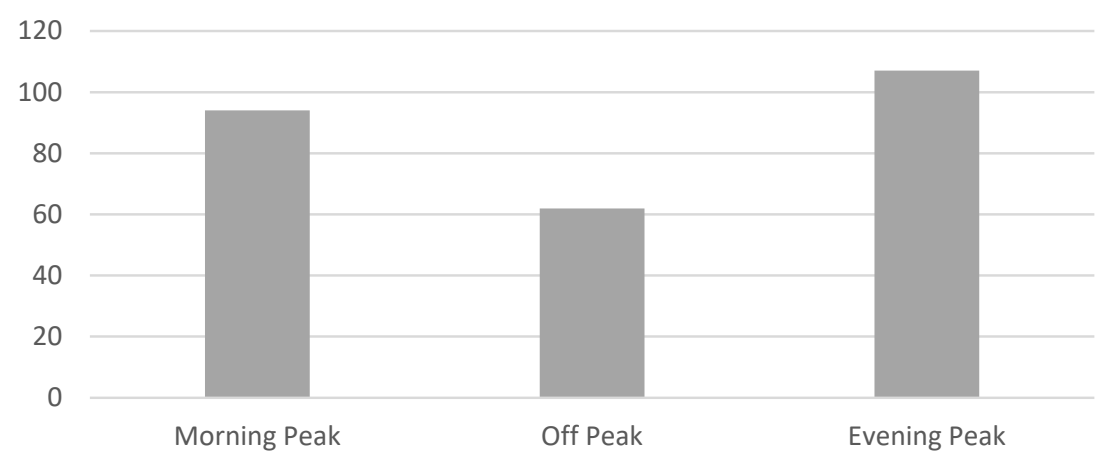

Figure 4. Number of metro stations without EMS support.

The spatial distribution of metro stations without EMS support is depicted in Figure 5. The kernel density method was used to measure the spatial distribution of metro stations without EMS support. As can be seen from Figure 5, the hot spot transfers from the city center to the suburb as the congestion is reduced. The number of metro stations without EMS support of different metro lines is depicted in Figure 6. If the station is a transfer station, the percentage of station is divided equally according to the number of transfer lines. During both the peak and off-peak hours, the line 6 and line 4 have the maximum number of stations without EMS support. Therefore, the metro managers should focus on the safety management of line 6 and line 4 .

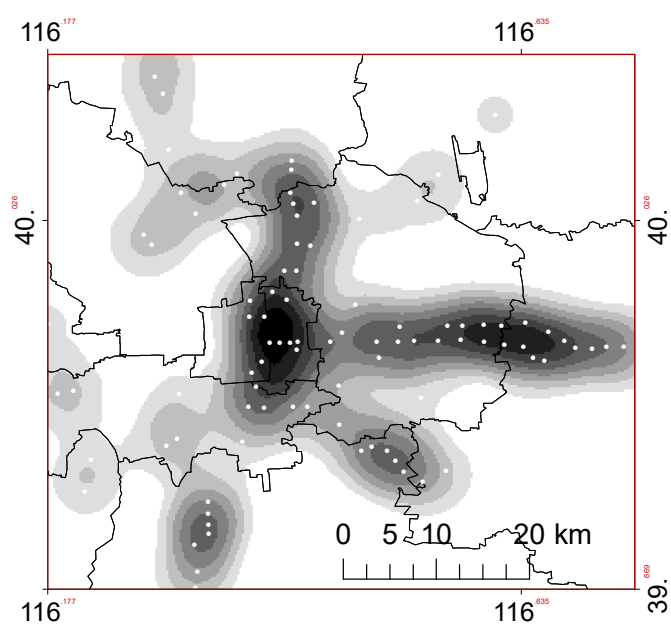

(a) Morning Peak Hours

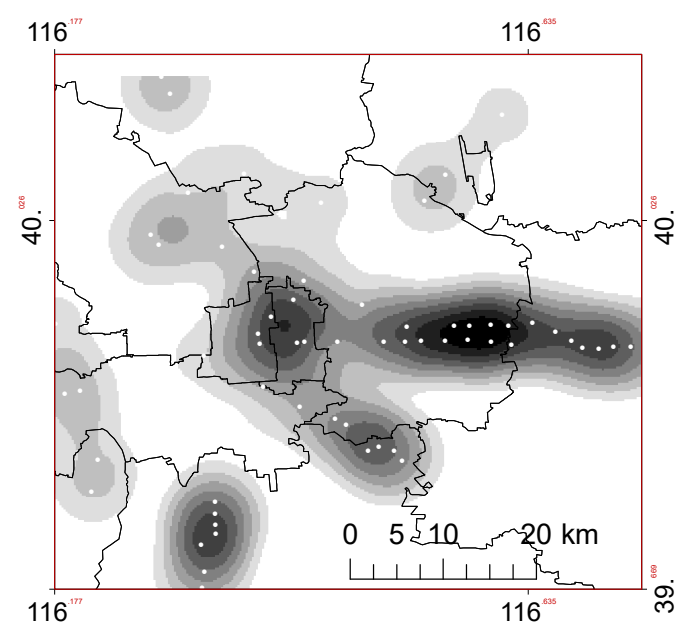

(b) Off Peak Hours

Figure 5. Cont. 


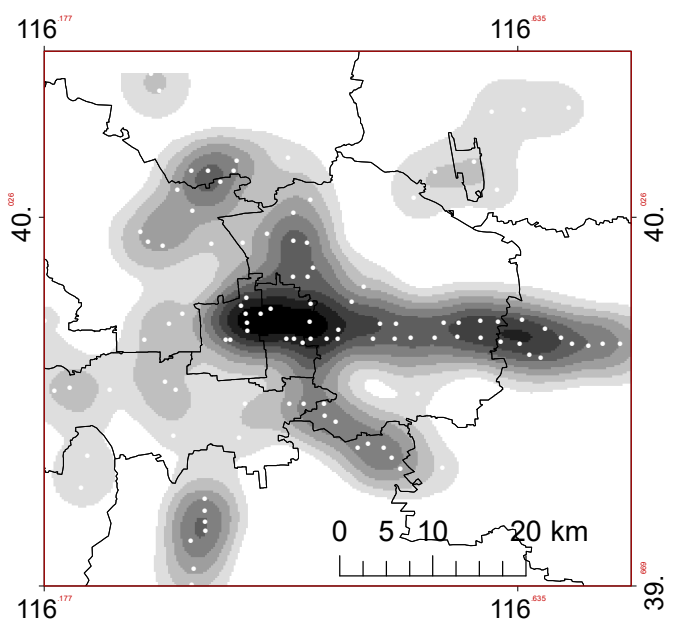

(c) Evening Peak Hours

Figure 5. Kernel density of metro stations without EMS support.

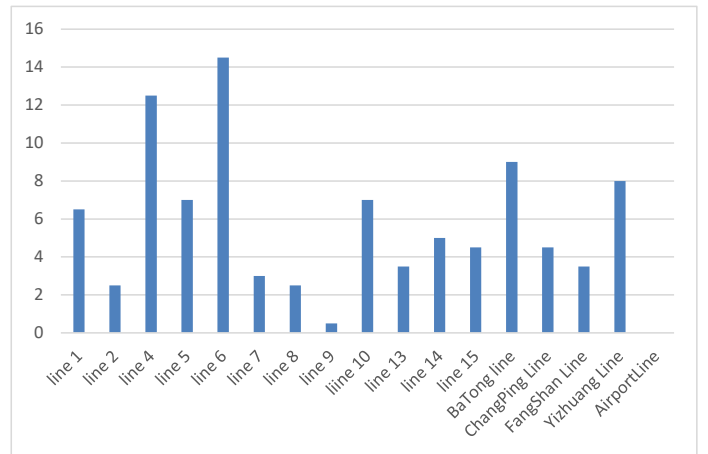

(a) Morning Peak Hours

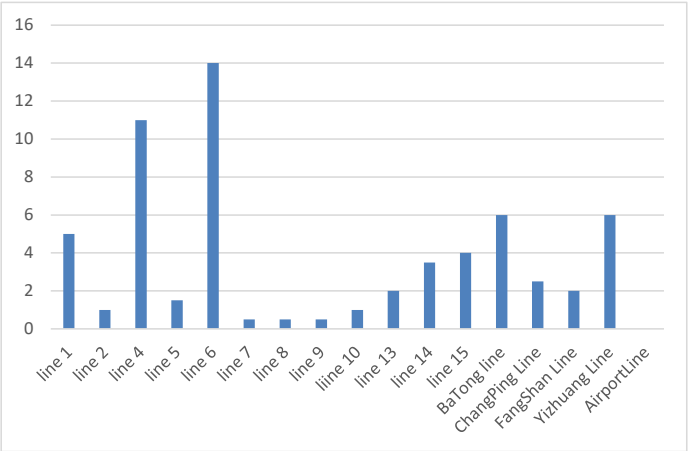

(b) Off Peak Hours

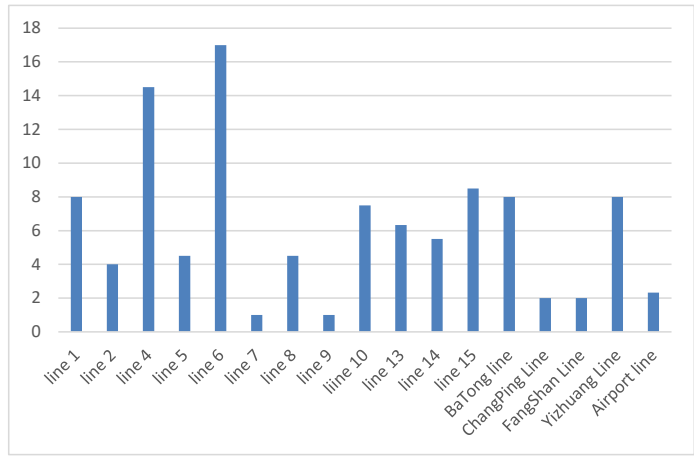

(c) Evening Peak Hours

Figure 6. Metro stations without EMS support of different lines.

(3) Most vulnerable ambulance stations

We want to find which ambulance stations have the largest impacts to the performance of EMS for metro stations, i.e., which ambulance station will decrease the selection diversity index the most when its medical rescue service is unavailable?

There are 121 ambulance stations in the EMS of Beijing, and we sort all ambulance stations as $\{1,2, \ldots, 121\}$. It is assumed that the ambulance station is busy or unavailable in turn. The selection diversity index and the vulnerability in each case can be calculated based on Equations (6) and (7). 
The result is shown in Figure 7. As indicated by Figure 7, the selection diversity in each case and the value of vulnerability varies obviously along with the ambulance station being unavailable in turn. The minimum value of selection diversity is $1.267,1.715$ and 1.177 during morning peak, off-peak and evening peak hours, respectively. The maximum value of vulnerability is $0.037,0.035$ and 0.031 during morning peak, off-peak hours and evening peak hours, respectively.

The top ten most vulnerable ambulance stations during different periods are marked in Figure 8. As indicated by Figure 8, the location results of top ten most vulnerable ambulance stations varies during different periods. The fact shows that the traffic status not only has much effect on the selection diversity but also can change the spatial distribution of vulnerability.

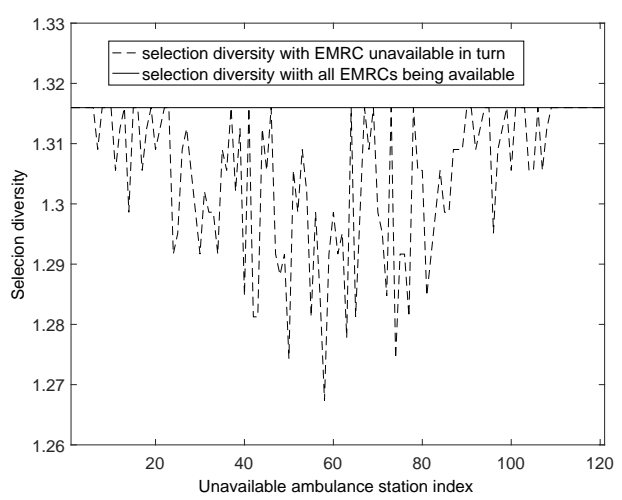

(a) Morning peak hours

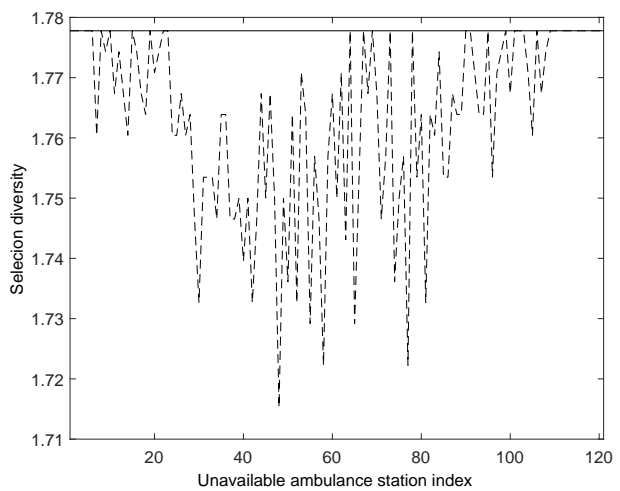

(c) Off-peak hours

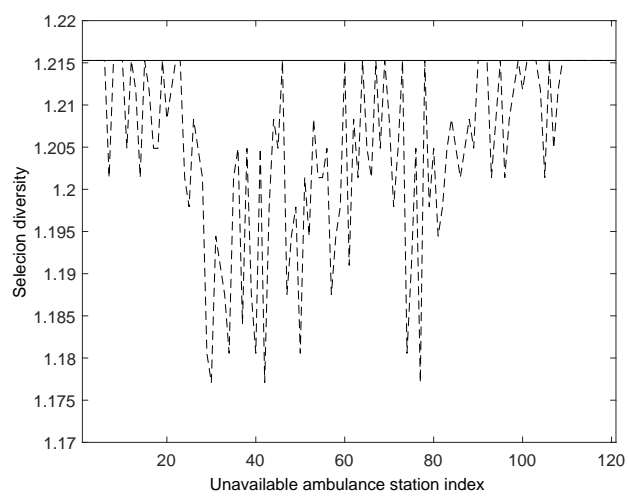

(e) Evening peak hours

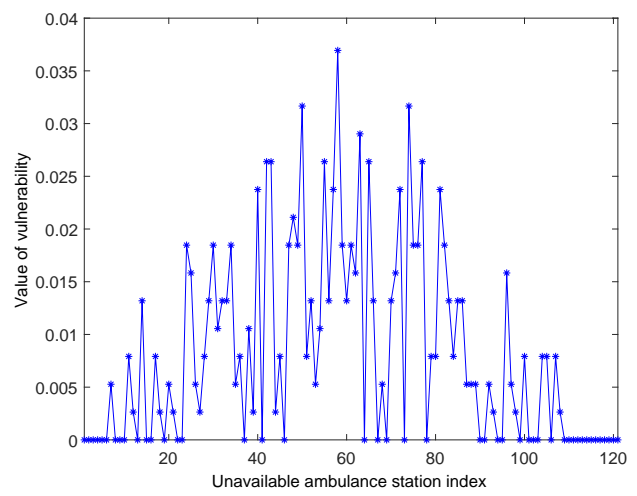

(b) Morning peak hours

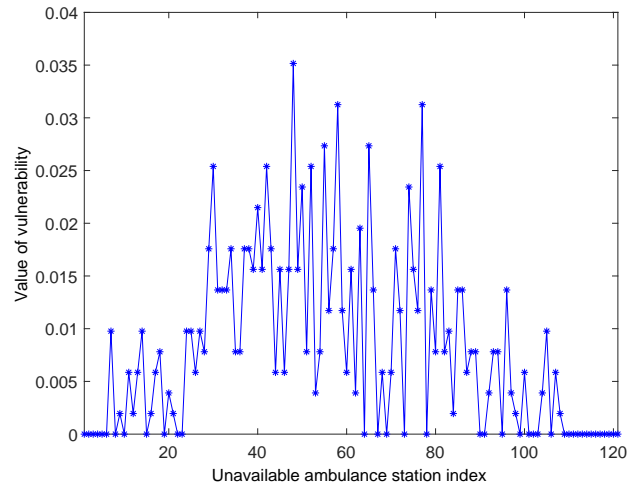

(d) Off-peak hours

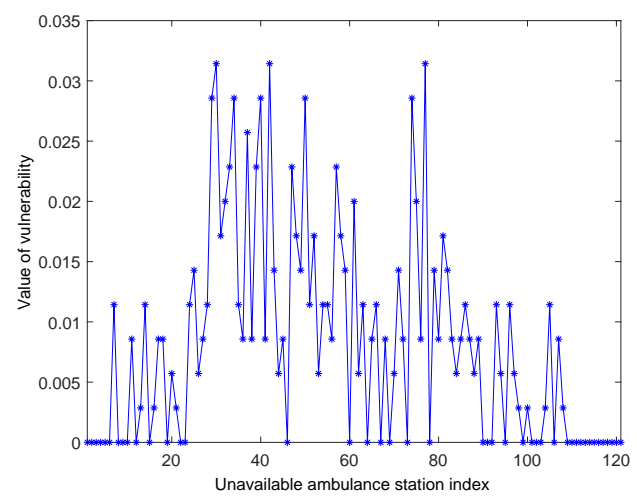

(f) Evening peak hours

Figure 7. Vulnerability analysis with ambulance station unavailable in turn. 


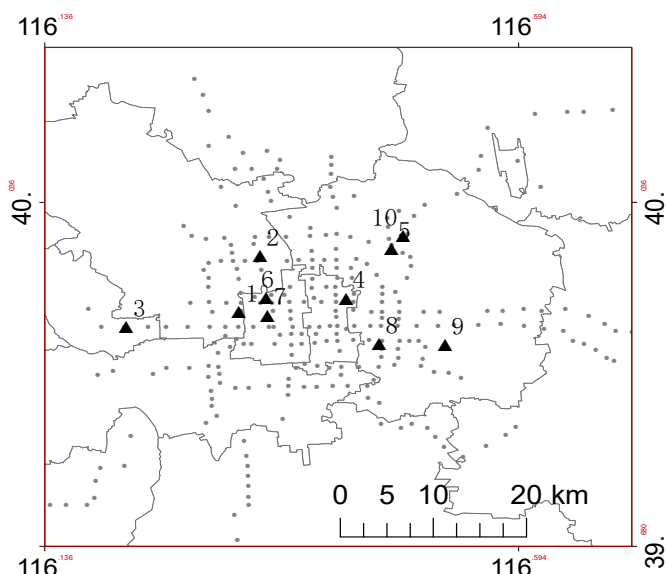

(a) Morning peak hours

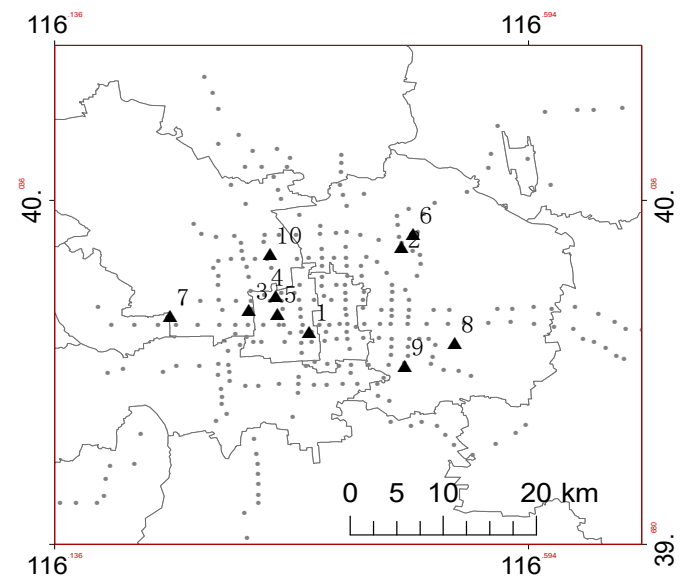

(b) Off-peak hours

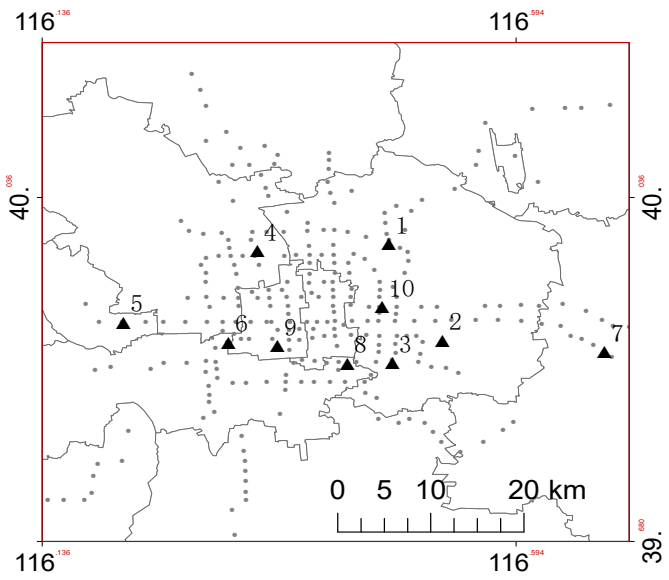

(c) Evening peak hours

Figure 8. Locations of most vulnerable ambulance stations.

The selection diversity and the vulnerability when the rescue service of the top ten vulnerable ambulance stations is unavailable in turn are presented in Table 1. For example, the vulnerability index is $0.026,0.031,0.031$ and the value of selection diversity is $1.281,1.722,1.177$ when ambulance station 77 is busy and other ambulance stations keep in normal operation during morning peak hours, off-peak hours and evening peak hours, respectively. It can be seen from Table 1 that the ambulance stations denoted by $42,74,77$ belong to the top ten most vulnerable ambulance stations during all periods; 6 ambulance stations denoted by $30,50,55,58,65,81$ belong to the top ten most vulnerable ambulance stations during two periods.

Table 1. Value of selection diversity and vulnerability with top 10 most vulnerable ambulance stations.

\begin{tabular}{ccccccccccc}
\hline 7:00-9:00 & & & & & & & & & & \\
\hline index & 58 & 74 & 50 & 63 & 77 & 65 & 55 & 43 & 42 & 81 \\
$S_{j}$ & 1.267 & 1.274 & 1.274 & 1.278 & 1.281 & 1.281 & 1.281 & 1.281 & 1.281 & 1.285 \\
$\rho_{j}$ & 0.037 & 0.032 & 0.032 & 0.029 & 0.026 & 0.026 & 0.026 & 0.026 & 0.026 & 0.024 \\
\hline 10:00-16:00 & & & & & & & & & & \\
\hline index & 48 & 77 & 58 & 65 & 55 & 81 & 52 & 42 & 30 & 74 \\
$S_{j}$ & 1.715 & 1.722 & 1.722 & 1.729 & 1.729 & 1.733 & 1.733 & 1.733 & 1.733 & 1.736 \\
$\rho_{j}$ & 0.035 & 0.031 & 0.031 & 0.027 & 0.027 & 0.025 & 0.025 & 0.025 & 0.025 & 0.023 \\
\hline
\end{tabular}


Table 1. Cont.

\begin{tabular}{ccccccccccc}
\hline 17:00-20:00 & \multicolumn{10}{c}{10} \\
\hline index & 77 & 42 & 30 & 74 & 50 & 40 & 34 & 29 & 37 & 57 \\
$S_{j}$ & 1.177 & 1.177 & 1.177 & 1.181 & 1.181 & 1.181 & 1.181 & 1.186 & 1.184 & 1.188 \\
$\rho_{j}$ & 0.031 & 0.031 & 0.031 & 0.029 & 0.029 & 0.029 & 0.029 & 0.029 & 0.026 & 0.023 \\
\hline
\end{tabular}

\section{Conclusions and Extension}

The main purpose of this paper is to develop the selection diversity index for measuring performance of EMS for metro stations and EMS vulnerability. First, the available ambulance stations for rescue of metro stations in emergency are defined based on the response time threshold. Then, the number of available ambulance stations can be calculated and the selection diversity index can be formulated to account for the average number of available ambulance stations for each metro station. Finally, the vulnerability index is proposed based on the selection diversity to evaluate the imperfect performance of EMS when the ambulance stations are busy and cannot provide rescue service.

The real-world case can answer the two fundamental questions described before for station and EMS managers: (1) "How many available ambulance stations are available or can serve the rescue of metro stations in emergency?", (2) "Which ambulance stations are most vulnerable?". First, the distribution of number of available ambulance stations during peak and off-peak hours is analyzed, the more congested the traffic network is, the lower the selection diversity is; Secondly, it is found that the daily traffic can affect not only the number but also the spatial distribution of metro stations without EMS support, the suggestion about the safety management of metro lines is also given based on the spatial distribution analysis. Finally, the most vulnerable ambulance stations are given so that the EMS managers can reallocate the EMS facilities even more appositely.

Further, the effect of the traffic system on the performance of EMS is measured by the selection diversity analysis. The number of available ambulance stations and the most vulnerable ambulance stations are changing with the time resulted from the dynamic traffic state and thus the EMS managers cannot ignore the effect of urban traffic state on the performance of EMS. The ambulance vehicles and other emergency resources should be allocated more reasonably after considering the real situations of traffic system and the integrated design of EMS and traffic system is necessary for improving urban safety. On the other hand, the results also proposed the distribution of metro stations without EMS support and thus the metro managers should focus on the safety management of metro stations without EMS support during different periods, not just crowed metro stations [49].

However, there is also a limitation of the proposed method framework. The most vulnerable ambulance stations are evaluated based on the selection diversity concept defined in this paper. It does not mean other ambulance stations are not vulnerable from other perspectives. For example, our current study does not consider the probability of ambulance stations being busy or unavailable. It would be interesting to examine how the vulnerable ambulance stations would change dynamically with the addition of uncertain emergency demand data.

For future research, we will use not only the travel time data but also the risk data of metro stations [50] to analyze the vulnerability and resiliency of system. In addition, it would be a good idea to test the selection diversity concept to other cities by long-term data collection. After the above works, the selection diversity can be used to assess the location plan of ambulance stations in future.

Author Contributions: Z.Z. proposed the idea and wrote the paper, L.J. and Y.Q. built the model and edited the figures.

Funding: The study is funded by the National Key research and development program of China (No. 2018YFB1201403) and the State Key Laboratory of Rail Traffic Control and Safety (Contract No. RCS2018ZT008). 
Acknowledgments: The study is supported by the State Key Laboratory of Rail Traffic Control and Safety (Contract No. RCS2018ZT008), Beijing Jiaotong University and the National Key R \& D Program of China (Grant number 2017YFB1201200).

Conflicts of Interest: The authors declare no conflict of interest.

\section{References}

1. Yang, Y.; Liu, Y.; Zhou, M.; Li, F.; Sun, C. Robustness assessment of urban rail transit based on complex network theory: A case study of the Beijing Subway. Saf. Sci. 2015, 79, 149-162. [CrossRef]

2. Jiang, C.; Deng, Y.; Hu, C.; Ding, H.; Chow, W.K. Crowding in platform staircases of a subway station in China during rush hours. Saf. Sci. 2009, 47, 931-938. [CrossRef]

3. Ma, T.; Xu, X.; Ning, J. Research on propagation laws of explosion shock wave inside metro station. J. Loss Prev. Process Ind. 2017, 46, 54-68. [CrossRef]

4. Zhao, D.; Jiang, J.; Zhou, R.; Tong, Y.; Wu, F.; Shi, L. Numerical study on the optimisation of smoke ventilation mode for interchange subway station fire. Int. J. Vent. 2016, 15, 79-93. [CrossRef]

5. Daskin, M.S. Application of an expected covering model to emergency medical service system design. Decis. Sci. 1982, 13, 416-439. [CrossRef]

6. Johnson, C.W. Using evacuation simulations for contingency planning to enhance the security and safety of the 2012 olympic venues. Saf. Sci. 2008, 46, 302-322. [CrossRef]

7. Schmid, M.; Deisenberg, M.; Strauss, H.; Schüttler, J.; Birkholz, T. Equipment of a land-based emergency medical service in Bavaria: A questionnaire. Der Anaesthesist 2006, 55, 1051-1057. [CrossRef] [PubMed]

8. Reilly, M.J.; Markenson, D.; DiMaggio, C. Comfort level of emergency medical service providers in responding to weapons of mass destruction events: Impact of training and equipment. Prehosp. Disaster Med. 2007, 22, 297-303. [CrossRef] [PubMed]

9. Toro-DíAz, H.; Mayorga, M.E.; Chanta, S.; Mclay, L.A. Joint location and dispatching decisions for emergency medical services. Comput. Ind. Eng. 2013, 64, 917-928. [CrossRef]

10. Li, Q.; Deng, Y.; Liu, C.; Zeng, Q.; Lu, Y. Modeling and analysis of subway fire emergency response: An empirical study. Saf. Sci. 2016, 84, 171-180. [CrossRef]

11. Zhong, M.; Shi, C.; Fu, T.; He, L.; Shi, J. Study in performance analysis of China Urban Emergency Response System based on Petri net. Saf. Sci. 2010, 48, 755-762. [CrossRef]

12. Rao, A. Counterexamples for the Location of Emergency Service Facilities. Oper. Res. 1974, 22, $1259-1261$. [CrossRef]

13. Li, X.; Zhao, Z.; Zhu, X.; Wyatt, T. Covering models and optimization techniques for emergency response facility location and planning: A review. Math. Methods Oper. Res. 2011, 74, 281-310. [CrossRef]

14. Başar, A.; Çatay, B.; Ünlüyurt, T. A taxonomy for emergency service station location problem. Optim. Lett. 2012, 6, 1147-1160. [CrossRef]

15. Cheng, Y.H.; Liang, Z.X. A strategic planning model for the railway system accident rescue problem. Transp. Res. Part E Logist. Transp. Rev. 2014, 69, 75-96. [CrossRef]

16. Taylor, B.M. Spatial modelling of emergency service response times. J. R. Stat. Soc. Ser. A (Stat. Soc.) 2017, 180, 433-453. [CrossRef]

17. Goldberg, J.B. Operations research models for the deployment of emergency services vehicles. EMS Manag. J. 2004, 1, 20-39.

18. Scott, D.W.; Factor, L.E.; Gorry, G.A. Predicting the response time of an urban ambulance system. Health Serv. Res. 1978, 13, 404. [PubMed]

19. Aringhieri, R.; Carello, G.; Morale, D. Ambulance Location through Optimization and Simulation: The Case of Milano Urban Area; Università Degli Studi di Milano, Polo Didattico e di Ricerca di Crema: Milan, Italiy, 2007.

20. Inoue, H.; Yanagisawa, S.; Kamae, I. Computer-simulated assessment of methods of transporting severely injured individuals in disaster: Case study of an airport accident. Comput. Methods Prog. Biomed. 2006, 81, 256-265. [CrossRef] [PubMed]

21. Wang, Y.; Luangkesorn, K.L.; Shuman, L. Modeling emergency medical response to a mass casualty incident using agent based simulation. Soc.-Econ. Plan. Sci. 2012, 46, 281-290. [CrossRef]

22. Silva, P.M.S.; Pinto, L.R. Emergency medical systems analysis by simulation and optimization. In Proceedings of the Winter Simulation Conference, Baltimore, MD, USA, 5-8 December 2010; pp. 2422-2432. 
23. Van Buuren, M.; van der Mei, R.; Aardal, K.; Post, H. Evaluating dynamic dispatch strategies for emergency medical services: TIFAR simulation tool. In Proceedings of the 2012 Winter IEEE Simulation Conference (WSC), Berlin, Germany, 9-12 December 2012; pp. 1-12.

24. Lee, T.; Cho, S.H.; Jang, H.; Turner, J.G. A simulation-based iterative method for a trauma center: Air ambulance location problem. In Proceedings of the Winter Simulation Conference, Berlin, Germany, 9-12 December 2012; p. 85.

25. Zhang, G.; Ma, J.; Lu, J. Emergency management evaluation by a fuzzy multi-criteria group decision support system. Stoch. Environ. Res. Risk Assess. 2009, 23, 517-527. [CrossRef]

26. Blackwell, T.H.; Kaufman, J.S. Response time effectiveness: Comparison of response time and survival in an urban emergency medical services system. Acad. Emerg. Med. 2002, 9, 288-295. [CrossRef] [PubMed]

27. Wilde, E.T. Do emergency medical system response times matter for health outcomes? Health Econ. 2013, 22, 790-806. [CrossRef] [PubMed]

28. Fitch, J. Response times: Myths, measurement \& management. JEMS J. Emerg. Med. Serv. 2005, 30, 47-56.

29. Wang, J.W.; Rong, L.L. Robustness of the western United States power grid under edge attack strategies due to cascading failures. Saf. Sci. 2011, 49, 807-812. [CrossRef]

30. Chen, C.; Huang, G.H.; Li, Y.P.; Zhou, Y. A robust risk analysis method for water resources allocation under uncertainty. Stoch. Environ. Res. Risk Assess. 2013, 27, 713-723. [CrossRef]

31. Beraldi, P.; Bruni, M.E.; Conforti, D. Designing robust emergency medical service via stochastic programming. Eur. J. Oper. Res. 2004, 158, 183-193. [CrossRef]

32. Zhang, Z.H.; Jiang, H. A robust counterpart approach to the bi-objective emergency medical service design problem. Appl. Math. Model. 2014, 38, 1033-1040. [CrossRef]

33. Shishebori, D.; Babadi, A.Y. Robust and reliable medical services network design under uncertain environment and system disruptions. Transp. Res. Part E Logist. Transp. Rev. 2015, 77, 268-288. [CrossRef]

34. Song, X.; Xie, Z.; Xu, Y.; Tan, G.; Tang, W.; Bi, J.; Li, X. Supporting real-world network-oriented mesoscopic traffic simulation on GPU. Simul. Model. Pract. Theory 2017, 74, 46-63. [CrossRef]

35. Alonso, B.; Pòrtilla, Á.I.; Musolino, G.; Rindone, C.; Vitetta, A. Network Fundamental Diagram (NFD) and traffic signal control: First empirical evidences from the city of Santander. Transp. Res. Procedia 2017, 27, 27-34. [CrossRef]

36. Polimeni, A.; Vitetta, A. Dynamic vehicle routing in road evacuation: A model for route design. WIT Trans. Built Environ. 2011, 116, 627-638.

37. Russo, F.; Rindone, C. Urban exposure: Training activities and risk reduction. WIT Trans. Ecol. Environ. 2014, 191, 991-1001.

38. Giovanna, C.; Giuseppe, M.; Antonio, P.; Corrado, R.; Francesco, R.; Antonino, V. Transport models and intelligent transportation system to support urban evacuation planning process. IET Intell. Transp. Syst. 2016, 10, 279-286. [CrossRef]

39. Baeza-Yates, B.V.; Castillo, C. Quality and Freshness in Web Crawling; Center for Web Research, Dept. of Computer Science, University of Chile: Santiago, Chile, 2002; pp. 1-10.

40. Zaki, A.S.; Cheng, H.K.; Parker, B.R. A simulation model for the analysis and management of an emergency service system. Soc.-Econ. Plan. Sci. 1997, 31, 173-189. [CrossRef]

41. Al-Ghamdi, A.S. Emergency medical service rescue times in Riyadh. Accid. Anal. Prev. 2002, 34, 499-505. [CrossRef]

42. Chaiken, J.M.; Larson, R.C. Methods for allocating urban emergency units. Manag. Sci. 1971, 19, P110-P130. [CrossRef]

43. Griffin, R.; McGwin, G. Emergency Medical Service Providers' Experiences with Traffic Congestion. J. Emerg. Med. 2013, 44, 398-405. [CrossRef] [PubMed]

44. Schmid, V.; Doerner, K.F. Ambulance location and relocation problems with time-dependent travel times. Eur. J. Oper. Res. 2010, 207, 1293-1303. [CrossRef] [PubMed]

45. Hu, S. Online mapping service for fire service first responders using google maps api. Pap. Appl. Geogr. Conf. 2012, 35, 52-61.

46. Hu, S.; Dai, T. Online Map Application Development Using Google Maps API, SQL Database, and ASP.NET. Int. J. Inf. Commun. Technol. Res. 2013, 3, 3.

47. $\mathrm{Xu}, \mathrm{Y}$; Z Zhang, Q.; Zheng, S. The rising demand for subway after private driving restriction: Evidence from Beijing's housing market. Reg. Sci. Urban Econ. 2015, 54, 28-37. [CrossRef] 
48. Center, B.T.R. Beijing Transportation Annual Report; Technical Report; Tsinghua University Press: Beijing, China, 2016.

49. Zhang, Z.; Jia, L.; Qin, Y.; Yun, T. Optimization-based feedback control of passenger flow in subway stations for improving level of service. Transp. Lett. 2017, 7, 1-12. [CrossRef]

50. Lu, Y.; Li, Q.; Xiao, W. Case-based reasoning for automated safety risk analysis on subway operation: Case representation and retrieval. Saf. Sci. 2013, 57, 75-81. [CrossRef]

(C) 2018 by the authors. Licensee MDPI, Basel, Switzerland. This article is an open access article distributed under the terms and conditions of the Creative Commons Attribution (CC BY) license (http://creativecommons.org/licenses/by/4.0/). 